\title{
ANALYSIS OF CARDIOVASCULAR RISK FACTORS BASED ON SCREENING QUESTIONNAIRE DATA
}

\section{Kocharova Tatijana ${ }^{1}$}

DOI: https://doi.org/10.30525/978-9934-571-89-3_82

With the influence of various factors on the body, including psycho-emotional and physical stress the reserve capabilities of the cardiovascular system play a significant role. The cardiovascular system is the most responsive to adverse environmental effects, therefore, it is an indicator of adaptive reactions [1, p. 510].

The effectiveness of preventive measures is largely due to the effectiveness of their conduct, the use of reliable statistical data and their in-depth analysis [2, p. 4].

The study should positively affect the prediction and prevention of cardiology diseases in general, which determines the relevance of this work.

\footnotetext{
${ }^{1}$ Kharkiv National Medical University, Ukraine
} 
The goal of our study is to analyze the information on the parameters of the cardiovascular system obtained by the method of Internet screening to determine the risk of cardiovascular disease.

A questionnaire, or a surveys, is one of the main technical methods of research conducting, which allows to obtain structured information in accordance to the planned research sequence, using the regulated procedure "question-answer".

The open responses by name, address, and address are provided to identify respondents. The required for the study list of questions involves getting closed responses for the categories, given bellow.

The open responses by name, address, and address are provided to identify respondents. The required for the investigation list of questions suggests closed responses on the problem categories, given bellow:

- General characteristics;

- Systolic arterial pressure;

- Hereditary and cardiovascular anamnesis;

- The presence of a history of type 2 diabetes;

- Physical activity;

- Smoking (active and passive);

- Use of alcohol;

- Sleep (the number of hours and difficulties associated with sleep);

- Stress (tendency to worry, sadness, irritability);

- Activity (by frequency and nature of activity).

The questionnaire was implemented with Google Forms, a part of the Google Docs office suite, which allows you to create online survey forms [3].

270 respondents both young and adult were interviewed. The results table are given on the figure 1.

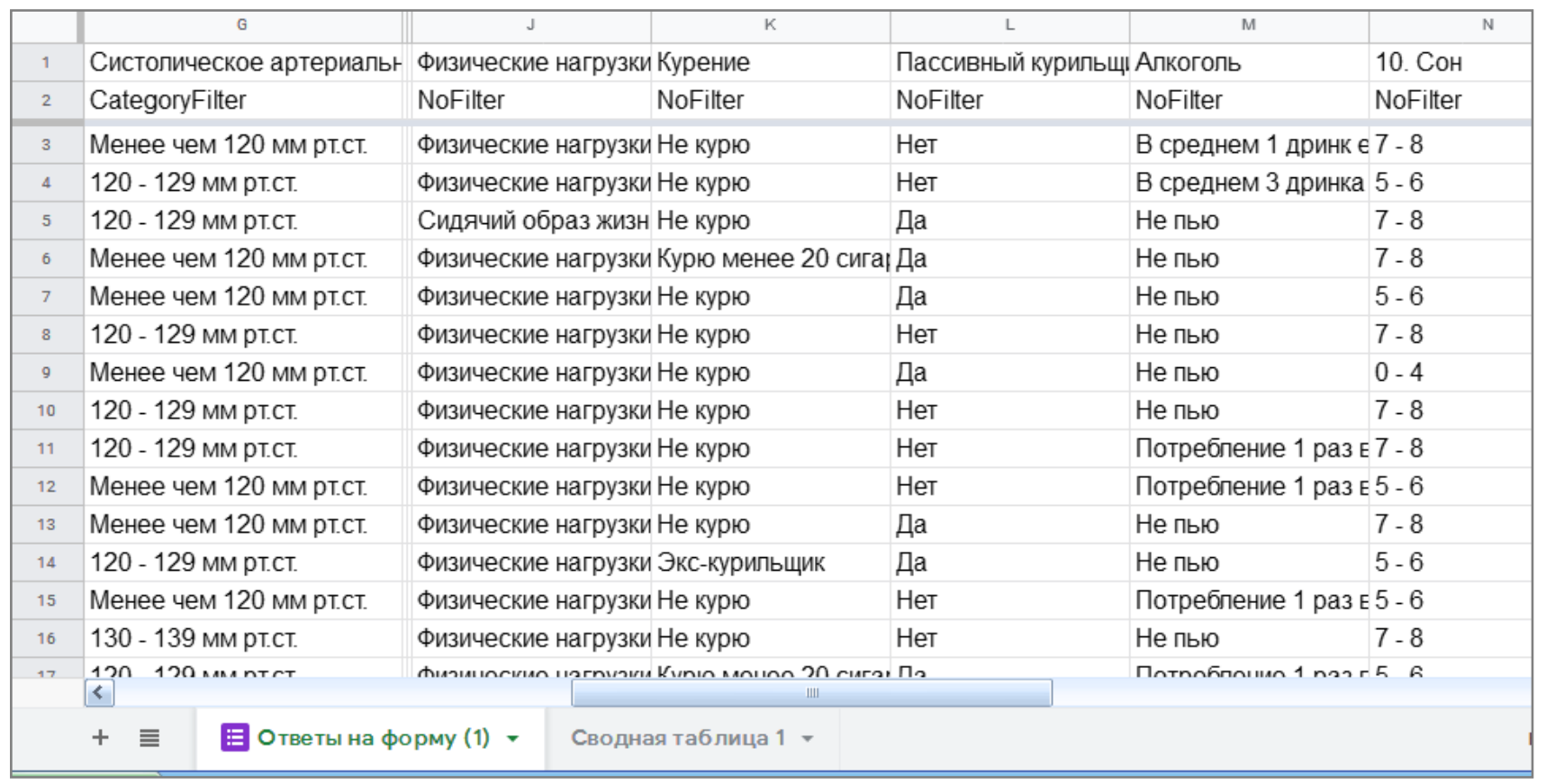

Figure 1. The answer table loaded in Excel 
A reference to the form "Questionnaire for the detection of cardiovascular risk factors” («Анкета для виявлення кардіоваскулярних факторів ризику» in the original) is placed on the website of the Ukrainian Association of Prophylactic Medicine (http://uapm.org.ua/uk) as banner. A printed questionnaire was also used.

It is known that in medical research a significant number of observations are qualitative. During to processing qualitative information, categorized variables are used, which are obtained by surveys data on nominal and ranking scales. Nominal scales give the simplest classification of objects. Such variables are often quite sufficient to evaluate the results of research. These include the respondents' answers to questions about sex, the presence of type 2 diabetes, diseases of hereditary and cardiovascular anamnesis, types of physical activity, stress, and how to remove it.

The study also uses more powerful scales - ordinal or rank scales. Unlike nominal, the objects in the ordinal scale are ordered (for example, gradations of sleep duration and systolic pressure, frequency of smoking, drinking alcohol, occurrence of destructive feelings of sadness, depression, hopelessness, apathy, despondency, helplessness, lack of interest in society, anxiety, fear, sudden feelings of panic, embarrassment, feelings of resentment or hostility).

The usage of mathematical analysis tools allows to give a numerical estimation of the phenomena being studied, regardless of their nature. Summary data about the number of objects with the same value give us to obtain different frequency indices.

Preliminary processing of the results presented in Excel spreadsheet processor has allowed to allocate the ratio of the frequency of occurrence of some negative and positive factors of cardiovascular risk.

The obvious problem is the lack of sleep, as $48.1 \%$ of the respondents sleep 5-6 hours a day, and $3.7 \%$ from 0 to 4 hours, and only $44.1 \%$ of respondents reaches the norm of sleep (7-8 hours per day), and $4.1 \%$ have a long sleep time. At the same time, $45.5 \%$ of the total number of respondents feel insomnia. And another $18.7 \%$ have a snoring problem.

The high percentage of non-smokers is positive (73\%) and $12.2 \%$ of those who dropped smoking. More than half (61.9\%) completely refuse alcohol, or 31.9\% use a one-time norm in 2 weeks.

The most common factors in stress relief are sports (48.6) and play with home pets (54.8). $26.7 \%$ use yoga and meditation. At the same time, a sedentary or rare physical activity less than 1 time per week is noted by $24.2 \%$ of respondents, $28.1 \%$ performs physical activity on average 1 time per week, $36.7 \%$ of the respondents perform regular physical activity (2-3 times a week).

Every week (about 30.2\%) and monthly (about 34.3\%), some respondents feel sorrow, depression, hopelessness, apathy, disbelief, helplessness, lack of interest in society, irritation or disorder, insult or hostility towards others, anxiety, fear, sudden panic feelings.

The considered researches show the presence of sufficient informative basis for revealing of factors of cardiovascular систем infringement. Timely assessment of the functional state of the cardiovascular system is able to detect early pathology processes at preclinical stages. 


\section{References:}

1. Abisheva Z.S. Iskakova U.B., Zhetpisbaeva G.D., Asan G.K., Zhurunova M.S., Raisov T.K., Ismagulova T.M., Dautova M.B. (2016). Izmenenie serdechno sosudistoy sistemy v pokoe [Changes in the cardiovascular system at rest]. International Journal of Applied and Basic Research, no 1-4, pp. 510-512.

2. Bakaeva O.A. (2013). Algoritm vybora ratsional'nogo sposoba proverki nalichiya zavisimosti mezhdu kategorial'nymi peremennymi pri donozologicheskom kontrole [Algorithm for choosing a rational method of checking the existence of a relationship between categorical variables in prenosological monitoring]. Information technologies for modeling and management, vol. 1, no. 79, pp. 4-11.

3. Solov'eva O. (2017). Vse vozmozhnosti Google Forms [All the features of Google Forms]. COO "Netology-group". Retrieved from: https://netology.ru/blog/google-formy (accessed: 9 March 2019) 